\title{
Sperm characteristics and in vitro fertilization ability of thawed spermatozoa from Black Manchega ram: Electroejaculation and postmortem collection
}

\author{
O. García-Álvarez ${ }^{\text {a }}$, A. Maroto-Morales a , F. Martínez-Pastor ${ }^{\text {b }}$, J.J. Garde ${ }^{\text {b }}$, \\ M. Ramón ${ }^{\text {a }}$, M.R. Fernández-Santos ${ }^{\mathrm{a}}$, M.C. Esteso ${ }^{\mathrm{c}}$, \\ M.D. Pérez-Guzmán ${ }^{\mathrm{a}}$, A.J. Soler Valls ${ }^{\mathrm{a}, \mathrm{b}, *}$ \\ ${ }^{a}$ Regional Center of Animal Selection and Reproduction (CERSYRA) JCCM, 13300 Valdepeñas, Spain \\ ${ }^{\mathrm{b}}$ Biology of Reproduction Group, National Wildlife Research Institute (IREC) UCLM-CSIC-JCCM, 02071 Albacete, Spain \\ ${ }^{\mathrm{c}}$ Animal Reproduction and Obstetrics, University of León, 24071 León, Spain
}

Received 4 November 2008; received in revised form 13 February 2009; accepted 17 February 2009

\begin{abstract}
The aim of this study was to assess two models of sperm collection on the quality and fertility of thawed spermatozoa from Black Manchega rams, a threatened breed. Sperm samples were collected by electroejaculation and postmortem from each male. Samples were diluted with Biladyl and frozen. Motility (subjective and objective by means of computer-assisted semen analysis), membrane integrity, and acrosomal status (microscopy) were assessed on fresh and thawed semen; plasmalemma integrity, mitochondrial membrane potential, DNA integrity, and acrosomal status were evaluated by flow cytometry on thawed semen. Thawed spermatozoa were used in a heterologous in vitro fertilization test. After thawing, the proportion of live spermatozoa with intact membrane (YO-PRO-1-/PI-) was higher for postmortem samples $(\mathrm{P}<0.001)$, although the ratio of YO-PRO-1- spermatozoa within the PI- population was higher for ejaculated samples $(\mathrm{P}=0.007)$. Likewise, the proportion of live spermatozoa having high mitochondrial membrane potential (MitoTracker+) and intact acrosomes (PNA-) was higher for postmortem samples (P $<0.001$ and $\mathrm{P}<0.001$, respectively). Considering only live spermatozoa, the ratio of MitoTracker+/PNA- cells was higher for electroejaculated samples $(\mathrm{P}=0.026$ and $\mathrm{P}=0.003)$. Both electroejaculated and postmortem samples fertilized oocytes. Nevertheless, electroejaculated samples yielded a higher percentage of hybrid embryos $(\mathrm{P}=0.041)$. In conclusion, although postmortem spermatozoa had better sperm quality after thawing, electroejaculated spermatozoa showed higher ratios for sperm quality when only the live population was considered. Electroejaculated and postmortem samples might be used for germplasm banking of this threatened breed, but the fertility of postmortem spermatozoa might be lower.
\end{abstract}

(C) 2009 Elsevier Inc. All rights reserved.

Keywords: Electroejaculated spermatozoa; Epididymal spermatozoa; Germplasm banking; Heterologous in vitro fertilization; Ram

* Corresponding author. Tel.: +34 967599 200x2552; fax: +34 967599238 .

\section{Introduction}

The Manchega sheep is an autochthonous dairy breed from Spain with a white and a black variety. Currently, there are few herds of Black Manchega sheep (around 2000 animals), and in Spain it is considered an 
endangered breed of special interest (RD 1682/1997). As recommended by the Food and Agriculture Organization (FAO) of the United Nations, endangered breeds must be preserved by ex situ and in situ means.

One of the ex situ procedures consists of the development of genetic resource banks, cryopreserving gametes and embryos, thus allowing to store genetic resources indefinitely [1]. Assisted reproductive technologies have been demonstrated to be successful tools to reproduce endangered species; sperm cryopreservation, in combination with artificial insemination, being the method that has been most extensively applied.

Semen can be collected from live animals by artificial vagina [2], but this technique requires a previous training period [3]. Electroejaculation is an alternative when males are not trained to artificial vagina. This method allowed the collection of highquality semen in Guirra ram without noticeable differences from semen collected by artificial vagina [4]. In that study, sperm quality was higher for electroejaculated samples even after cryopreservation.

Postmortem recovery of spermatozoa and their use has received much less attention in sheep than in other domestic species [5,6]. Collection and cryopreservation of epididymal spermatozoa is a useful method to rescue germplasm of dead animals that would be otherwise lost and use it to preserve endangered breeds. This kind of sample has been successfully cryopreserved and used for artificial insemination or in vitro fertilization in other ungulates, such as red deer [7-13].

Ejaculated spermatozoa have a lower cryosurvival and osmotic resistance than that of epididymal spermatozoa [14]. Nevertheless, it has been showed that adding seminal plasma to epididymal spermatozoa protects against the effects of cooling and freezing $[15,16]$. However, seminal plasma can also have detrimental effects on cryosurvival [17].

In vitro fertility of fresh semen obtained by artificial vagina and postmortem has been studied in sheep [5]. However, to date no studies have been conducted in this species for evaluating the effect of collection method (electroejaculation or postmortem recovery) on postthawing sperm quality and fertility.

Considering this background, the objective of this study was to evaluate the postthawing sperm quality and in vitro fertility of sperm samples obtained both by electroejaculation and by postmortem collection from Black Manchega rams in order to assess its suitability for germplasm banking and the differences between both methodologies.

\section{Materials and methods}

\subsection{Animals and reagents}

All animal procedures were performed in accordance with the Spanish Animal Protection Regulation RD 1201/2005, which conforms to European Union Regulation 2003/65. Six rams of the Black Manchega breed (age $>3 \mathrm{yr}$ ) were used. Males came from a private farm, whose owner decided to sacrifice these animals within a genetic improvement program, a practice compatible with the protection plans for the breed. Rams were temporally maintained and managed at the Regional Center of Animal Selection and Reproduction (Valdepeñas, Spain), in order to recover and cryopreserve their semen before and after sacrifice. These males had not been trained to artificial vagina.

Chemicals were of reagent grade and were purchased from Sigma (Madrid, Spain). Fluorescence probes were purchased from Invitrogen (Barcelona, Spain), except for propidium iodide (PI) and peanut agglutinin conjugated with fluorescein isothiocyanate (PNAFITC), which were obtained from Sigma. Chromatographically purified acridine orange was purchased from Polysciences Inc. (Warrington, PA, USA).

\subsection{Semen collection}

Semen samples were collected by electroejaculation and postmortem from epididymis from the same males. Previous to electroejaculation (15 min before), males received an intramuscular injection of xylazine. (0.2 $\mathrm{mg} \mathrm{kg}^{-1}$ body weight; Rompun $2 \%$; Bayer S.A., Barcelona, Spain). The rectum was cleaned of feces, and the preputial area was shaved and washed with physiologic saline serum. Electroejaculation was carried out using a three-electrode probe $(250 \mathrm{~mm} \times 25 \mathrm{~mm})$ connected to a power source that allowed voltage and amperage control (P.T. Electronics, Boring, OR, USA). Semen was collected into a graduated collection vial at $37{ }^{\circ} \mathrm{C}$.

For the postmortem collection, the testicles of each male were obtained at a slaughterhouse and transported at room temperature, arriving at the laboratory between 0.5 and $1 \mathrm{~h}$ afterward. Testicles with epididymides attached were isolated from scrotum. Epididymal spermatozoa were collected performing several incisions on each cauda epididymis with a surgical blade, placing the sperm suspension in $1 \mathrm{~mL}$ phosphatebuffered saline (PBS; pH 7.5, $310 \mathrm{mOsm} / \mathrm{kg}$ ).

After sperm collection, sperm motility, percentage of spermatozoa with intact acrosome assessed by phase- 
147 Q3 $37{ }^{\circ} \mathrm{C}$, covered with a $22 \times 22$ coverslip and examined

148 (three fields at least) with a phase-contrast microscope 149 Q4 (Nikon 80i, negative contrast optics) with a warming 150 state at $37{ }^{\circ} \mathrm{C}$. Analysis was carried out using the Sperm 151 Class Analyzer software (SCA2002; Microptic, Barce152 lona, Spain), and the following parameters were used 153 for the study: average path velocity ( $\mu \mathrm{m} / \mathrm{sec}$; VAP), 154 linearity (\%; LIN), amplitude of the lateral movement 155 of the head $(\mu \mathrm{m} ; \mathrm{ALH})$, and beat cross-frequency $(\mathrm{Hz}$; $156 \mathrm{BCF})$.

\subsection{Cryopreservation} 162 diluted to $400 \times 10^{6}$ spermatozoa $/ \mathrm{mL}$ with Biladyl, 163 Fraction $\mathrm{A}$, at $30{ }^{\circ} \mathrm{C}$. Diluted semen was cooled to $5{ }^{\circ} \mathrm{C}$ 164 for $2 \mathrm{~h}$ and then was further diluted with the same volume 165 of Biladyl, Fraction B. Sperm samples were allowed to 166 equilibrate at $5{ }^{\circ} \mathrm{C}$ for $2 \mathrm{~h}$ and packed in $0.25-\mathrm{mL}$ plastic 167 straws. Finally, they were frozen in a programmable 168 biofreezer (IceCube 14S ver. 1.30; SY-LAB Geräte 169 Q6 GmbH Minitüb) at $20{ }^{\circ} \mathrm{C} / \mathrm{min}$ to $-100{ }^{\circ} \mathrm{C}$, and at $10{ }^{\circ} \mathrm{C}$ / 170 min from $-100{ }^{\circ} \mathrm{C}$ to $-140{ }^{\circ} \mathrm{C}$, and then plunged into 171 liquid nitrogen. The straws remained for a minimum 172 period of 6 months in liquid nitrogen before thawing was 173 carried out.

\subsection{Assessment of frozen-thawed spermatozoa}

Thawing was performed by dropping the straws (two per male at a time, and per collection method) in a water bath with $5 \mathrm{~L}$ of saline serum at $37{ }^{\circ} \mathrm{C}$ for $20 \mathrm{sec}$. Q7 Thawed spermatozoa were layered on a Percoll discontinuous density gradient (45\%/90\%) and centrifuged at $700 \times g$ for $10 \mathrm{~min}$ in order to eliminate the particles of egg yolk and enrich the sample in highly motile spermatozoa. After centrifugation, the supernatant was carefully removed with a pipette, leaving a volume of $0.1 \mathrm{~mL}$ of sperm suspension at the bottom of each tube. Sperm samples were evaluated for sperm motility, acrosomal status by phase-contrast (\%; NAR), viability by nigrosin-eosin (\%; Viability), and motility by CASA in the same way as that for fresh sperm samples. After this evaluation, sperm suspension was incubated at $37^{\circ} \mathrm{C}$ for $2 \mathrm{~h}$, and then sperm motility, acrosomal status (\%; NAR), and viability (\%; Viability) were assessed as previously described.

In addition, two more straws were thawed for the assessment of the seminal quality by flow cytometry. We assessed the membrane status with YO-PRO-1, the mitochondrial membrane potential with MitoTracker Deep Red, the acrosome integrity with peanut agglutinin Q8 conjugated with fluorescein isothiocyanate, (FITCPNA), and the viability (membrane integrity) with propidium iodide (PI).

We prepared two staining solutions using flow cytometer sheath fluid (BD FACSFlow). One of them Q9 was prepared with $3 \mathrm{nM}$ Hoechst 33342 (stock: $9 \mu \mathrm{M}$ in Milli-Q water), $50 \mathrm{nM}$ YO-PRO-1 (stock: $100 \mu \mathrm{M}$ in DMSO), $15 \mu \mathrm{M}$ PI (stock: 7.5 mM in Milli-Q water), and 100 nM MitoTracker Deep Red (stock: 1 mM in DMSO). The other solution was prepared with $3 \mathrm{nM}$ Hoechst 33342, $15 \mu \mathrm{M}$ PI, and $10 \mu \mathrm{g} / \mathrm{mL}$ PNA-FITC (stock of $0.2 \mathrm{mg} / \mathrm{mL}$ in $\mathrm{dH}_{2} \mathrm{O}$ ). We diluted the sample in $0.5 \mathrm{~mL}$ of each staining solution in polypropylene tubes for flow cytometry $\left(5 \times 10^{6}\right.$ spermatozoa/mL). The tubes were allowed to rest for $15 \mathrm{~min}$ in the dark and then analyzed using a Becton Dickinson LSR-I flow cytometer (BD Biosciences, San José, CA, USA). We used the three lasers of the cytometer to excite the different fluorochromes. A 325-nm helium-cadmium UV laser was used for exciting the Hoechst 33342, a 488-nm argon-ion laser was used for exciting YO-PRO-1, PNA-FITC, and PI, and a 633-nm helium-neon laser was used for exciting MitoTracker Deep Red. We acquired the forward-scatter light (FSC) and side-scatter light (SSC) signals plus the fluorescence light of each fluorochrome using four photodetectors. FL1 was used for YO-PRO-1 and PNAFITC (530/28BP filter), FL3 for PI (670LP filter), FL5 for Hoechst 33342 (424/44BP filter), and FL6 for MitoTracker Deep Red (670/40BP filter). The acquisition was controlled using the Cell Quest Pro 3.1 software (BD Biosciences). All the parameters were read using logarithmic amplification. We set up an acquisition template in the software that allowed us first to discriminate spermatozoa from debris within the events acquired. FSC/SSC and FL5/FL3 (Hoechst 33342 vs. PI) dot-plots were used to discard debris. The filtered events were displayed in dot-plots showing either FL1/FL3 (YO-PRO-1 vs. PI or PNA-FITC vs. PI) and FL6/FL3 (MitoTracker Deep Red vs. PI). We acquired 10,000 spermatozoa from each sample, saving the data in FCS Q10 237 ver. 2 files. The analysis of the flow cytometry data was carried out using WinMDI ver. 2.8 (The Scripps Research Institute, La Jolla, CA, USA). 
YO-PRO-1-/PI- spermatozoa were considered as viable (non-"apoptotic," intact membrane), MitoTracker+/PI- spermatozoa as viable with high mitochondrial membrane potential, and PNA-/PI- spermatozoa as viable with intact acrosome. Also, we calculated the ratios of YO-PRO-1-, MitoTracker+, and PNA- within live spermatozoa population (PI-).

Chromatin stability was assessed by using the Sperm Chromatin Structure Assay (SCSA) technique (SCSA Diagnostics, Inc., Brookings, SD, USA) [22]. This technique is based in the susceptibility of the sperm DNA to acid-induced denaturation in situ and in the metachromatic staining Acridine Orange (AO). This stain fluoresces green when combined with doublestranded DNA and red when combined with singlestranded DNA (denatured). This technique has been used in ram with good results [23,24]. Thawed spermatozoa were diluted with TNE buffer $(0.15 \mathrm{M}$ $\mathrm{NaCl}, 0.01 \mathrm{M}$ Tris $\mathrm{HCl}, 1 \mathrm{mM}$ ethylenediamine tetraacetic acid [EDTA]; $\mathrm{pH}=7.4$ ) to $2 \times 10^{6}$ cells $/ \mathrm{mL}$. Samples were flash frozen in LN2 and stored at $-80{ }^{\circ} \mathrm{C}$ until analysis. For the analysis, the samples were thawed on crushed ice, and $200 \mu \mathrm{L}$ was put on a cytometry tube. Then, we added $400 \mu \mathrm{L}$ of an aciddetergent solution $(0.08 \mathrm{M} \mathrm{HCl}, 0.15 \mathrm{M} \mathrm{NaCl}, 0.1 \%$ Triton X-100; $\mathrm{pH}=1.2$ ). Exactly $30 \mathrm{sec}$ after adding the acid-detergent solution, we added $1.2 \mathrm{~mL}$ of staining solution $(6 \mu \mathrm{g} / \mathrm{mL}$ AO in a buffer containing $37 \mathrm{mM}$ citric acid, $126 \mathrm{mM} \mathrm{Na} \mathrm{HPO}_{4}, 1.1 \mathrm{mM}$ disodium EDTA, and $150 \mathrm{mM} \mathrm{NaCl}$; $\mathrm{pH}=6$ ). After $3 \mathrm{~min}$, the sample was run through a Becton Dickinson LSR-1 flow cytometer. Acridine Orange was excited using an argon laser providing 488-nm light. The red fluorescence was detected using a long-pass (670LP) filter (FL-3) and the green one using a band-pass (530/28BP) filter (FL-1). Sample acquisition was carried out with CellQuest ver. 3 software. Flow cytometry data (FCS files) were processed and saved as tabbed text using WinMDI ver. 2.8 (The Scripps Research Institute, La Jolla, California). We calculated the DNA Fragmentation Index (DFI) for each spermatozoon as the ratio of red fluorescence with respect to total fluorescence (red + green), expressed as a percentage. High values of DFI indicate chromatin abnormalities. We also calculated $\%$ DFI, as the percentage of spermatozoa with DFI $>25$, and High DNA Stainability (HDS) as the percentage of the spermatozoa with green fluorescence higher than channel 600 (of 1024 channels).

Thawed semen was incubated at $37{ }^{\circ} \mathrm{C}$ for $2 \mathrm{~h}$ in the same freezing extender, and all sperm parameters previously cited, except chromatin stability, were assessed by flow cytometry.

\subsection{Heterologous in vitro fertilization}

We carried out a heterologous in vitro fertilization (IVF) test to assess the fertilizing potential of electroejaculated and postmortem sperm samples, as this assay is highly related with the in vivo fertility as described by García-Álvarez et al. [25]. We performed heterologous IVF four times per male and method collection, and a minimum of 20 oocytes per well were used. Ovaries were collected at a slaughterhouse from heifers about $1 \mathrm{yr}$ old and transported to our laboratory in saline solution $\left(30{ }^{\circ} \mathrm{C}\right)$ between 1 and $2 \mathrm{~h}$ after removal. Immature oocytes were collected from the ovaries using a 19gauge needle, in TCM-199 supplemented with HEPES $(2.39 \mathrm{mg} / \mathrm{mL})$, heparin $(2 \mu \mathrm{L} / \mathrm{mL})$, and gentamicin $(40 \mu \mathrm{g} / \mathrm{mL})$. Aspirated cumulus-oocyte complexes (COCs) were washed in TCM-199gentamicin $(40 \mu \mathrm{g} / \mathrm{mL})$, selecting those with dark homogeneous cytoplasm and surrounded by tightly packed cumulus cells. These COCs were placed in 4well plates containing $500 \mu \mathrm{L}$ TCM-199 supplemented with cysteamine $(100 \mu \mathrm{M})$ and epidermal growth factor (EGF; $10 \mathrm{ng} / \mathrm{mL}$ ) and matured at $38.5{ }^{\circ} \mathrm{C}$ in $5 \%$ $\mathrm{CO}_{2}$. After $24 \mathrm{~h}, \mathrm{COCs}$ were washed in synthetic oviduct fluid (SOF) supplemented with essential and nonessential amino acids [26] and $10 \%$ of estrous sheep serum, and cumulus cells were removed by gentle pipetting. Oocytes (minimum 20 oocytes per well) were transferred to 4 -well plates with $400 \mu \mathrm{L}$ of fertilization medium (SOF supplemented with $10 \%$ of estrous sheep serum and $40 \mu \mathrm{g} / \mathrm{mL}$ gentamicin) under mineral oil.

Thawed samples (electroejaculated and epididymal) were centrifuged through a Percoll discontinuous density gradient $(45 \% / 90 \%)$ and were capacitated in the fertilization medium for $10 \mathrm{~min}$. Sperm was coincubated with oocytes at a final concentration of $10^{6}$ spermatozoa/ $\mathrm{mL}$ at $38.5{ }^{\circ} \mathrm{C}$ in $5 \% \mathrm{CO}_{2}$.

Oocytes were evaluated visually with an inverted microscope (Nikon Eclipse TE2000-U) $40 \mathrm{~h}$ later for cleavage (two to eight cells). Then, the oocytes were fixed and stained with Hoechst 33342 to confirm the fertilization by the presence of two or more nuclei (\% cleavage).

\subsection{Statistical analysis}

Statistical analyses were carried out using SPSS ver. 15.0 (SPSS Inc., Chicago, IL, USA). A GLM ANOVA Q11339 tested the effect of collection method (electroejaculation vs. postmortem recovery) on sperm quality for 
Table 1

Effect of collection method (electroejaculation and postmortem recovery) on sperm quality in fresh and thawed samples from six Black Manchega rams

\begin{tabular}{|c|c|c|c|c|c|c|c|c|}
\hline \multirow[t]{2}{*}{ Sperm samples } & \multirow[t]{2}{*}{ Collection method } & \multicolumn{7}{|c|}{ Sperm parameter } \\
\hline & & $\mathrm{SM}(\%)$ & NAR $(\%)$ & Viability (\%) & $\operatorname{VAP}(\mu \mathrm{m} / \mathrm{sec})$ & $\operatorname{LIN}(\%)$ & $\mathrm{ALH}(\mu \mathrm{m})$ & $\mathrm{BCF}(\mathrm{Hz})$ \\
\hline \multirow[t]{3}{*}{ Fresh } & Electroejaculation & $74.17 \pm 3.96$ & $94.33 \pm 0.66$ & $82.00 \pm 1.69$ & $194.58 \pm 13.99$ & $66.86 \pm 4.65$ & $5.93 \pm 0.80$ & $10.0 \pm 0.59$ \\
\hline & Postmortem & $76.67 \pm 2.10$ & $93.50 \pm 1.05$ & $94.67 \pm 0.61$ & $175.47 \pm 6.62$ & $60.95 \pm 3.11$ & $8.32 \pm 1.09$ & $8.38 \pm 0.46$ \\
\hline & $\mathrm{P}$ value & 0.590 & 0.520 & $\leq 0.001$ & 0.245 & 0.316 & 0.108 & 0.058 \\
\hline \multirow[t]{3}{*}{ Thawed } & Electroejaculation & $36.67 \pm 7.60$ & $63.00 \pm 15.35$ & $45.00 \pm 7.13$ & $76.29 \pm 4.80$ & $61.24 \pm 5.53$ & $4.37 \pm 0.50$ & $7.67 \pm 0.47$ \\
\hline & Postmortem & $57.50 \pm 4.78$ & $93.17 \pm 1.01$ & $60.50 \pm 7.09$ & $117.26 \pm 8.14$ & $62.64 \pm 2.57$ & $5.48 \pm 0.51$ & $6.78 \pm 0.28$ \\
\hline & $P$ value & 0.043 & 0.078 & 0.154 & 0.001 & 0.823 & 0.156 & 0.138 \\
\hline
\end{tabular}

Data are means \pm SEM. SM, sperm motility; NAR, spermatozoa with intact acrosome; VAP, average path velocity; LIN, linearity; ALH, amplitude of the lateral movement of the head; BCF, beat cross-frequency.

Table 2

Effect of collection method (electroejaculation and postmortem recovery) on parameters evaluated by flow cytometry in thawed and incubated sperm samples from six Black Manchega rams

\begin{tabular}{lllllll}
\hline Sperm samples & Collection method & Sperm parameter & & \\
\cline { 3 - 6 } & & YO-PRO-1-/PI- (\%) & PNA-/PI- (\%) & MitoTracker+/PI- (\%) & $\%$ DFI \\
\hline Thawed & Electroejaculation & $24.91 \pm 6.08$ & $23.92 \pm 5.39$ & $24.49 \pm 6.11$ & $21.42 \pm 3.29$ & $0.26 \pm 0.02$ \\
& Postmortem & $65.98 \pm 1.53$ & $65.28 \pm 1.90$ & $62.71 \pm 1.90$ & $15.86 \pm 1.83$ & $0.28 \pm 0.06$ \\
& P value & $\leq 0.001$ & $\leq 0.001$ & $\leq 0.001$ & 0.171 & 0.729 \\
Incubated & Electroejaculation & $11.11 \pm 3.10$ & $11.72 \pm 3.19$ & $18.82 \pm 3.34$ & - & - \\
& Postmortem & $28.55 \pm 1.68$ & $29.35 \pm 1.96$ & $29.65 \pm 2.79$ & - & - \\
& P value & 0.001 & 0.001 & 0.032 & -
\end{tabular}

Data are means \pm SEM. YO-PRO-1-/PI-, live spermatozoa with intact membrane; PNA-/PI-, live spermatozoa with intact acrosome; MitoTracker+/PI-, live spermatozoa with high mitochondrial membrane potential; \%DFI, percentage of spermatozoa with DFI (DNA Fragmentation Index) higher than 25\%; HDS, spermatozoa with high DNA stainability (green fluorescence higher than channel 600).

fresh, thawed, and incubated sperm samples and on heterologous in vitro fertility for thawed sperm samples. Data were split into two groups according to collection method (electroejaculation or postmortem recovery), and Pearson rank correlations were carried out to study the relationships between percent cleavage and sperm quality. Also, stepwise multiple regression analyses were carried out in order to predict the percent cleavage from quality analyses for fresh, thawed, and incubated samples. Significance was set at $\mathrm{P}<0.05$.

\section{Results}

Sperm quality of fresh samples was not different between collection methods, except for sperm viability,

Table 3

Ratios of YO-PRO-1-, PNA-, and MitoTracker+ (considering PI- subpopulation) in thawed and incubated sperm samples recovered by electroejaculation and postmortem (epididymis) from six Black Manchega rams

\begin{tabular}{lllll}
\hline Sperm samples & Collection method & Sperm parameter & \\
\cline { 3 - 5 } & & YO-PRO-1- $(\%)$ & PNA- $(\%)$ & MitoTracker+ $(\%)$ \\
\hline Thawed & Electroejaculation & $93.45 \pm 0.57$ & $97.92 \pm 0.52$ & $92.32 \pm 1.69$ \\
& Postmortem & $90.58 \pm 0.62$ & $93.95 \pm 0.88$ & $86.59 \pm 1.40$ \\
Incubated & P value & 0.007 & 0.003 & 0.026 \\
& Electroejaculation & $54.97 \pm 5.32$ & $89.29 \pm 2.32$ & $77.62 \pm 1.27$ \\
& Postmortem & $48.22 \pm 2.83$ & $79.33 \pm 1.52$ & $49.20 \pm 3.94$ \\
& P value & 0.290 & 0.005 & $\leq 0.001$
\end{tabular}

Data are means \pm SEM. All data considering only the PI- spermatozoa subpopulation: YO-PRO-1-, spermatozoa with intact membrane; PNA-, spermatozoa with intact acrosome; MitoTracker+, spermatozoa with high mitochondrial membrane potential. 
which was higher in postmortem samples $(\mathrm{P}<0.001)$ (Table 1).

After thawing, sperm motility and velocity were higher in postmortem samples $(\mathrm{P}=0.043$ and $\mathrm{P}=0.001$, respectively) (Table 1 ). There were significant differences between electroejaculated and postmortem samples for most of the parameters evaluated by flow cytometry, with lower values for electroejaculated spermatozoa (YO-PRO-1-/PI-, $\mathrm{P}<0.001 ;$ PNA-/PI-, $\mathrm{P}<0.001$; MitoTracker+/PI-, $\mathrm{P}<0.001$ ) (Table 2). However, considering the live spermatozoa population (PI-), the electroejaculated samples yielded a higher ratio of YO-PRO-1$(\mathrm{P}=0.007), \quad$ PNA- $(\mathrm{P}=0.003)$ and MitoTracker+ $(\mathrm{P}=0.026)$ spermatozoa (Table 3). Moreover, the cleavage rate after the heterologous IVF was higher for electroejaculated spermatozoa (32.69\% vs. $21.84 \%$, $\mathrm{P}=0.041$ ) (Fig. 1).

After incubation, sperm motility and the percentage of spermatozoa with intact acrosome (subjectively assessed) were higher for postmortem samples $(34.16 \pm 3.87 \%$ vs. $10.00 \pm 4.74 \%, P=0.004$, and $74.33 \pm 6.35 \%$ vs. $19.25 \pm 7.78 \%, \quad \mathrm{P}=0.001$, respectively). We did not find significant differences between the collection methods for sperm viability (electroejaculated $33.83 \pm 5.92 \%$ and postmortem $24.00 \pm 7.25 \%, \mathrm{P}=0.324)$. The percentages of $\mathrm{YO}$ PRO-1-/PI-, PNA-/PI-, and MitoTracker+/PI- were higher in postmortem samples $(\mathrm{P}=0.001, \mathrm{P}=0.001$, and $\mathrm{P}=0.032$, respectively) (Table 2). However, considering only the PI- ("live") spermatozoa population, the ratios of PNA- and MitoTracker+ were higher

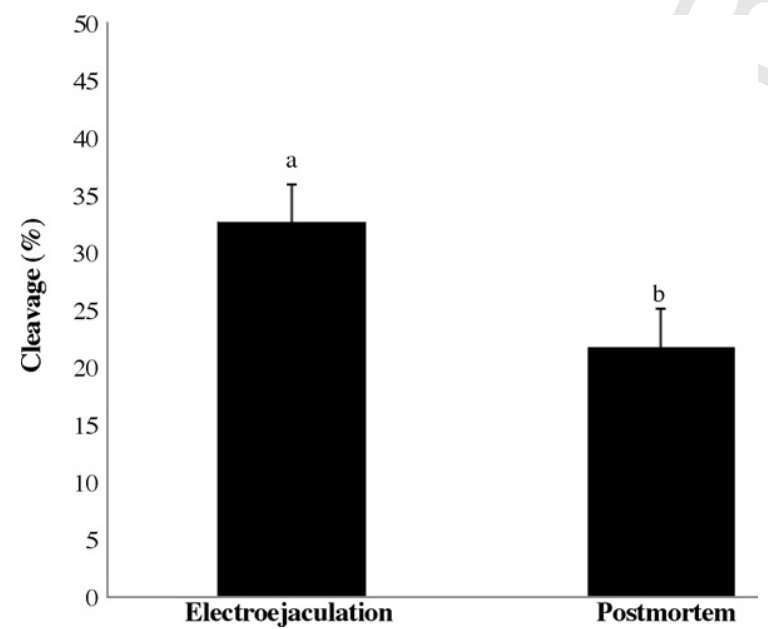

Fig. 1. Cleavage rate for thawed sperm samples obtained by electroejaculation and postmortem (epididymis) from Black Manchega rams. ${ }^{a, b}$ Bars with different letters indicate statistically significant differences $(P=0.041)$.
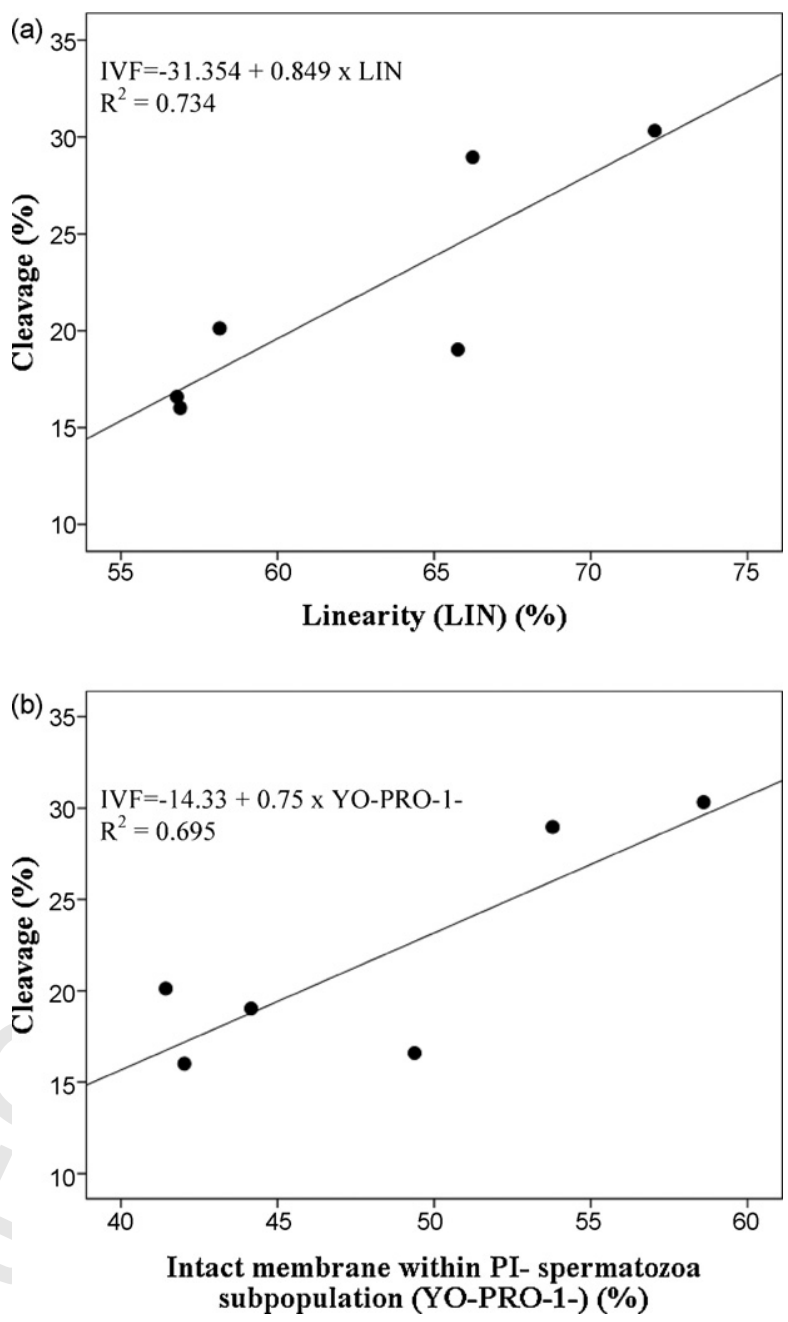

Fig. 2. Relationship between cleavage rate and different sperm parameters for samples obtained postmortem (epididymis) from Black Manchega rams. (A) Relationship between cleavage rate and linearity (LIN) in thawed sperm samples. (B) Relationship between cleavage rate and YO-PRO-1- within the PI- spermatozoa subpopulation in incubated sperm samples.

for electroejaculated samples $(\mathrm{P}=0.005$ and $\mathrm{P}<0.001$, respectively) (Table 3 ).

We also studied the relationships between spermquality parameters and cleavage rate for samples obtained by electroejaculation and those obtained from the epididymis postmortem. For fresh sperm samples, any parameter was correlated with the percent cleavage for both kinds of samples (electroejaculated and postmortem). However, for thawed sperm samples recovered from the epididymis postmortem, there was a correlation between LIN and cleavage rate $(r=0.85, P=0.029)$. Incubated samples displayed a relationship between the ratio of YO-PRO-1- within the PI- spermatozoa subpopula- 
tion and the fertility in postmortem samples $(r=0.83$, $\mathrm{P}=0.039$ ).

Stepwise multiple regression analyses were used to select a set of sperm-quality variables in fresh, thawed, and incubated samples that best predicted fertility (cleavage rate) in the samples collected by electroejaculation and postmortem. For fresh sperm samples obtained either by electroejaculation or postmortem, any parameter was predictive of the fertility. For thawed epididymal samples, LIN was the only predictor of fertility $\left(\mathrm{r}^{2}=0.73, \mathrm{P}=0.029\right)$ (Fig. $\left.2 \mathrm{~A}\right)$. After incubation, the ratio of YO-PRO-1- within the PI- subpopulation in postmortem samples was the only predictor of fertility $\left(r^{2}=0.69, P=0.039\right)($ Fig. $2 B)$.

\section{Discussion}

In this study, we assessed the effect of collection method (electroejaculation and postmortem) on sperm quality for fresh, thawed, and incubated samples and on in vitro fertility from Black Manchega rams. Both collection methods provided good sperm quality. Electroejaculation is an excellent choice for animals that have not been trained to artificial vagina, whereas postmortem collection can be used as an emergency method when valuable males die suddenly.

Our results showed that sperm quality for fresh samples was similar for electroejaculated and epididymal spermatozoa, although the viability was higher for epididymal spermatozoa (postmortem recovery). Other authors have studied the effect of collection method in other species. Blash et al. [27] compared the quality of epididymal spermatozoa and semen obtained by artificial vagina from goat bucks. These authors showed that for fresh samples, the viability was higher in epididymal spermatozoa, results that agree with the findings of this study. However, in other species such as red deer, the viability was higher in electroejaculated samples than in those obtained postmortem [21]. It is difficult to explain why these studies differed with ours, as different methodologies (collection and analyses) were used in these studies.

Cryopreservation, as expected, substantially reduced sperm viability in both kinds of samples (electroejaculated and postmortem), yielding better results for postmortem samples. Recent studies showed that electroejaculated samples had lower resistance than did epididymal spermatozoa when submitted to cryobiologically stressful conditions such as chilling, osmotic stress, and addition and removal of cryoprotective agents [14]. In our study, sperm quality of electroejaculated samples was worse than that of epididymal samples, after thawing. Nevertheless, the ratios for YO-PRO-1-, PNA-, and MitoTracker+ spermatozoa, considering the live spermatozoa subpopulation, were lower for epididymal spermatozoa, suggesting a higher heterogeneity, which may have contributed to their lower fertility results.

With respect to the IVF results, our outcomes do not agree with those obtained by Kaabi et al. [5], who found that ram epididymal and ejaculated spermatozoa rendered similar results in an IVF test. Our results may differ because Kaabi et al. [5] obtained ejaculated spermatozoa using artificial vagina, not electroejaculation, and because of rearing or breed differences. Furthermore, Blash et al. [27] did not find differences after an IVF assay using ejaculated and epididymal spermatozoa from goat. However, they found a higher pregnancy rate for ejaculated samples. Other authors showed that ejaculated bull spermatozoa had a higher binding ability to zona pellucida than that of those obtained postmortem from the same animals [28].

Spermatozoa complete their maturation during their transport along epididymis [29]. Evenson and Wixon [30] described that lack of appropriate sperm maturation resulted in increased DNA stainability (HDS). Our results showed that there were no differences in HDS between electroejaculated and epididymal spermatozoa. Likewise, \%DFI, indicative of DNA fragmentation, was not different for both collection methods (electroejaculation and postmortem, recovery). García-Macías et al. [23] found in ram that spermatozoa obtained from cauda epididymis had highly condensed chromatin, similar to that of ejaculated samples obtained by artificial vagina. Our data confirm that electroejaculated and postmortem samples have similar maturity indexes and that, although epididymal spermatozoa are more resistant to cryopreservation, this procedure affects similarly both types of samples regarding chromatin status.

The differences in IVF could be explained by considering that electroejaculated and epididymal spermatozoa respond differently to the capacitation treatments of the IVF protocol used in this study. A very important difference between both kinds of samples is that ejaculated spermatozoa contact the seminal plasma. Recent papers have revealed important roles for a number of proteins found in seminal plasma, which act in the regulation of in vitro capacitation [31]. Thus, Maxwell et al. [32] suggested that components of seminal plasma were responsible for the improved pregnancy rate after the resuspension of frozen-thawed ram spermatozoa in a medium containing seminal 
plasma. However, in recent studies, the addition of seminal plasma to ejaculated semen did not improve the pregnancy rate in cervically inseminated ewes [33], and the addition of seminal plasma to epididymal spermatozoa accelerated cell death in other cases [34]. In the current study, it is impossible to know if the higher fertility of ejaculated sperm samples was due to the action of seminal plasma or to the intrinsic characteristics of ejaculated cells.

We obtained correlations between several quality parameters and fertility only for the samples obtained postmortem, possibly due to their higher heterogeneity. These correlations were not found in fresh samples but appear after thawing with LIN (linearity) and after incubation with the ratio of YO-PRO-1- in the PIsubpopulation. Both LIN [35] and membrane integrity $[36,37]$ have been found to be good predictors of fertilization and pregnancy rate. It is possible that epididymal sperm samples with a lower ratio of YOPRO-1-, therefore with a predominant subpopulation of "apoptotic" spermatozoa (YO-PRO-1+/PI-) in the PIsubpopulation, were announcing a lower fertilizing ability.

Our results allow us to conclude that it is possible to obtain ram spermatozoa of good quality and freezability both by electroejaculation and postmortem. Therefore, these methods might be used to preserve semen of endangered breeds, either when males have not been trained for artificial vagina (electroejaculation), in case of sudden death, or as a last resource in the case that males must be removed from herds (postmortem recovery). Nevertheless, in vitro fertility was higher for thawed spermatozoa recovery by electroejaculation. Further studies are necessary to explain this difference and to improve IVF protocols for epididymal spermatozoa.

\section{Acknowledgments}

This work was supported by the Education and Science Council (PBI-05-011), by the Spanish Ministry of Education and Science (RZ2006-00006-C3), and by the Agriculture Council (PREG-05-004) of Junta de Comunidades de Castilla-La Mancha (JCCM). The authors thank Frimancha Industrias Cárnicas S.A. for their collaboration in the collection of the ovaries used in this work. Olga García-Álvarez and Alejandro Maroto Morales were recipients of scholarships from INIA and JCCM, respectively. Felipe Martínez-Pastor, María Rocío Fernández-Santos, and Milagros C. Esteso were supported by the Juan de la Cierva program from the Spanish Ministry of Education and Science. We are grateful to Alfonso Bisbal and Carol Body (English language teacher) for help in editing the manuscript.

\section{References}

[1] Watson PF, Holt WV. Organizational Issues Concerning the Establishment of a Genetic Resource Bank. In: Watson PF, Holt WV, editors. Cryobanking the Genetic Resource. Wildlife Conservation the Future?. Taylor \& Francis; 2001. p. 86-112.

[2] Salamon S, Evans G, Maxwell WMC. Inseminación artificial de ovejas y cabras. Editorial ACRIBIA, S.A., 1990, pp. 87-95.

[3] Wulster-Radcliffe MC, Williams MA, Stellflug JN, Lewis GS Technical note: artificial vagina vs. a vaginal collection vial for collecting semen from rams. J Anim Sci 2001;79:2964-7.

[4] Marco-Jiménez F, Puchades S, Gadea J, Vicente JS, Viudes-deCastro MP. Effect of semen collection method on pre- and postthaw Guirra ram spermatozoa. Theriogenology 2005;64:175665.

[5] Kaabi M, de Paz P, Álvarez M, Anel E, Boixo JC, Rouissi H, et al. Effect of epididymis handling conditions on the quality of ram spermatozoa recovered postmortem. Theriogenology 2003; 60:1249-59.

[6] Ehling C, Rath D, Struckmann C, Frenzel A, Schindler L, Niemann H. Utilization of frozen-thawed epididymal ram semen to preserve genetic diversity in Scrapie susceptible sheep breeds. Theriogenology 2006;66:2160-4.

[7] Soler AJ, García AJ, Fernández-Santos MR, Esteso MC, Garde JJ. Effects of thawing procedure on post-thawed in vitro viability and in vivo fertility of red deer epididymal spermatozoa cryopreserved at $-196^{\circ} \mathrm{C}$. J Androl 2003;24:746-56.

[8] Martínez-Pastor F, García-Macías V, Ávarez M, Herráez P, Anel L, de Paz P. Sperm subpopulation in Iberian red deer epididymal sperm and their changes through the cryopreservation process. Biol Reprod 2005;72:316-27.

[9] Soler AJ, Esteso MC, Fernández-Santos MR, Garde JJ. Characteristics of Iberian red deer (Cervus elaphus hispanicus) spermatozoa cryopreserved after storage at $5{ }^{\circ} \mathrm{C}$ in the epididymis for several days. Theriogenology 2005;64:1503-17.

[10] Fernández-Santos MR, Esteso MC, Montoro V, Soler AJ, Garde JJ. Cryopreservation of Iberian red deer (Cervus elaphus hispanicus) epididymal spermatozoa: effects of egg yolk, glycerol and cooling rate. Theriogenology 2006;66:1931-42.

[11] Martínez-Pastor F, García-Macías V, Esteso MC, Anel E, Fernández-Santos MR, Soler AJ, et al. A pilot study on post-thawing quality of Iberian red deer spermatozoa (epididymal and electroejaculated) depending on glycerol concentration and extender osmolality. Theriogenology 2006;66:1165-72.

[12] Gomendio M, Malo AF, Soler AJ, Fernández-Santos MR, Esteso MC, García AJ, et al. Male fertility and sex ratio at birth in red deer. Science 2006;314:1445-7.

[13] Soler AJ, Poulin N, Fernández-Santos MR, Cognie Y, Esteso MC, Garde JJ, Mermillod P. Heterologous in vitro fertility evaluation of cryopreserved Iberian red deer epididymal spermatozoa with zona-intact sheep oocytes and its relationship with the characteristics of thawed spermatozoa. Reprod Domest Anim 2008;43:293-8.

[14] Varisli O, Uguz C, Agca C, Agca Y. Motility and acrosomal integrity comparisons between electro-ejaculated and epididymal ram sperm after exposure to a range of anisosmotic solutions, cryoprotective agents and low temperaturas. Anim Reprod Sci 2009;110:256-68. 
[15] Barrios B, Pérez-Pe R, Gallego M, Tato A, Osada J, MuiñoBlanco T. Seminal plasma proteins revert the cold-shock damage on ram sperm membrane. Biol Reprod 2000;63:1531-7.

[16] Martínez-Pastor F, Anel L, Guerra C, Álvarez M, Soler AJ, Garde JJ, et al. Seminal plasma improves cryopreservation of Iberian red deer epididymal sperm. Theriogenology 2006;66: 1847-56.

[17] Kawano N, Shimada M, Terada T. Motility and penetration competence of frozen-thawed miniature pig spermatozoa are substantially altered by exposure to seminal plasma before freezing. Theriogenology 2004;61:351-64.

[18] Malo AF, Garde JJ, Soler AJ, García AJ, Gomendio M, Roldan ERS. Male fertility in natural populations of red deer is determined by sperm velocity and the proportion of normal spermatozoa. Biol Reprod 2005;72:822-9.

[19] Malo AF, Roldan ERS, Garde JJ, Soler AJ, Gomendio M. Antlers honestly advertise sperm production and quality. Proc R Soc B 2005;272:149-57.

[20] Malo AF, Gomendio M, Garde JJ, Lang-Lenton B, Soler AJ, Roldan ERS. Sperm design and sperm function. Biol Lett 2006;2:246-9.

[21] Martínez F, Martínez-Pastor F, Álvarez M, Fernández-Santos MR, Esteso MC, de Paz P, et al. Sperm parameters on Iberina red deer: electroejaculation and postmortem collection. Theriogenology 2008;70:216-26.

[22] Evenson DP, Higgins PJ, Grueneberg D, Ballachey BE. Flow cytometric analysis of mouse spermatogenic function following exposure to ethylnitrosourea. Cytometry 1985;6:238-53.

[23] García-Macias V, Martínez-Pastor F, Álvarez M, Garde JJ, Anel E, Anel L, de Paz P. Assessment of chromatin status (SCSA $($ ) in epididymal and ejaculated sperm in Iberian red deer, ram and domestic dog. Theriogenology 2006;66:1921-30.

[24] García-Macias V, Martínez-Pastor F, Álvarez M, Borragan S, Chamorro CA, Soler AJ, et al. Seasonal changes in sperm chromatin condensation in ram (Ovis aries), Iberian red deer (Cervus elaphus hispanicus) and brown beer (Ursus arctos). J Androl 2006;27:837-46.

[25] García-Alvarez O, Maroto-Morales A, Martínez-Pastor F, Fernández-Santos MR, Esteso MC, Pérez-Guzmán MD, Soler AJ. Heterologous in vitro fertilization is a good procedure to assess the fertility of thawed ram sperm. Theriogenology 2009;71:643-50.

[26] Gardner DK, Lane M, Spitzer A, Batt PA. Enhanced rates of cleavage and development for sheep zygotes cultured to the blastocyst stage in vitro in the absence of serum and somatic cells: amino acids, vitamins, and culturing embryos in groups stimulate development. Biol Reprod 1994;50:390-400.

[27] Blash S, Melican D, Gavin W. Cryopreservation of epididymal sperm obtained at necropsy from goats. Theriogenology 2000; 54:899-905.

[28] Ellington JE, Wilker CW, Hillman RB, Ball BA. Ability of epididymal or ejaculated bull spermatozoa to bind to cow zonae before and after oviduct epithelial cell co-culture. Theriogenology 1993;39:213.

[29] Yanagimachi R. Mammalian Fertilization. In: Knobil E, Neil J, editors. The Physiology of Reproduction. Plenum Press; 1988. p. $135-85$.

[30] Evenson DP, Wixon R. Clinical aspects of sperm DNA fragmentation detection and male infertility. Theriogenology 2006; 65:979-91.

[31] Fraser LR, Adeoya-Osiguwa SA, Baxendale RW, Gibbons R. Regulation of mammalian sperm capacitation by endogenous molecules. Front Biosci 2006;11:1636-45.

[32] Maxwell WM, Evans G, Mortimer ST, Gillan L, Gellatly ES, McPhie CA. Normal fertility in ewes after cervical insemination with frozen-thawed spermatozoa supplemented with seminal plasma. Reprod Fert Dev 1999;11:123-6.

[33] O'Meara CM, Donovan A, Hanrahan JP, Duffy P, Fair S, Evans ACO, Lonergan P. Resuspending ram spermatozoa in seminal plasma after cryopreservation does not improve pregnancy rate in cervically inseminated ewes. Theriogenology 2007;67: 1262-8

[34] Way AL, Griel LC, Killian GJ. Effects of accessory sex gland fluid on viability, capacitation, and the acrosome reaction of cauda epididymal bull spermatozoa. J Androl 2000;21:213-9.

[35] Bollendorf A, Check JH, Lurie D. Evaluation of the effect the absence of sperm with rapid and lineal progressive motility on subsequent pregnancy rates following intrauterine insemination and in vitro fertilization. J Androl 1996;17:550-7.

[36] Tartaglione CM, Ritta MN. Prognostic value of spermatological parameters as predictors of in vitro fertility of frozen-thawed bull semen. Theriogenology 2004;62:1245-52.

[37] Selvaraju S, Ravindra JP, Ghosh J, Gupta PSP, Suresh KP. Evaluation of sperm functional attributes in relation to in vitro sperm-zona pellucida binding ability and cleavage rate in assessing of frozen thawed buffalo (Bubalus bubalis) semen quality. Anim Reprod Sci 2008;106:311-21. 